\title{
Correction to: LncRNA PTAR promotes EMT and invasionmetastasis in serous ovarian cancer by competitively binding miR-101- $3 p$ to regulate ZEB1 expression
}

Haihai Liang ${ }^{1,2+}$, Tong $\mathrm{Yu}^{1,2+}$, Yue Han ${ }^{3+}$, Hua Jiang ${ }^{1,2}$, Chengyu Wang ${ }^{3}$, Tianyi You ${ }^{3}$, Xiaoguang Zhao ${ }^{1,2}$, Huitong Shan ${ }^{1,2}$, Rui Yang ${ }^{1,2}$, Lida Yang ${ }^{1,2}$, Hongli Shan ${ }^{1,2}$ and Yunyan Gu 4,5* $^{*}$

Correction to: Mol Cancer (2018) 17:119

https://doi.org/10.1186/s12943-018-0870-5

Following publication of the original article [1], the authors identified some minor errors in image-typesetting in Figs. 3, 4 and 7. Specifically, the following panels have been corrected:

Figure 3B

Figure $4 \mathrm{~A}$

Figure 4D

Figure 7D

The corrected figures are given below. The corrections do not have any effect on the final conclusions of the paper.
Science and Technology, Harbin Medical University, Harbin 150001, China. ${ }^{4}$ Department of Systems Biology, College of Bioinformatics Science and Technology, Harbin Medical University, Harbin 150086, China. ${ }^{5}$ Training Center for Students Innovation and Entrepreneurship Education, Harbin Medical University, Harbin 150086, China.

Published online: 09 April 2021

\section{Reference}

1. Liang $H$, Yu T, Han $Y$, et al. LncRNA PTAR promotes EMT and invasionmetastasis in serous ovarian cancer by competitively binding miR-101-3p to regulate ZEB1 expression. Mol Cancer. 2018;17:119 https://doi.org/10.1186/ s12943-018-0870-5.

\section{Author details}

'Department of Pharmacology (State-Province Key Laboratories of Biomedicine-Pharmaceutics of China, Key Laboratory of Cardiovascular Research, Ministry of Education), College of Pharmacy, Harbin Medical University, Harbin, China. ${ }^{2}$ Translational Medicine Research and Cooperation Center of Northern China, Heilongjiang Academy of Medical Sciences, Harbin 150081, China. ${ }^{3}$ Department of Systems Biology, College of Bioinformatics

The original article can be found online at https://doi.org/10.1186/s12943018-0870-5

* Correspondence: guyunyan@ems.hrbmu.edu.cn

${ }^{+}$Haihai Liang, Tong Yu and Yue Han contributed equally to this work. ${ }^{4}$ Department of Systems Biology, College of Bioinformatics Science and Technology, Harbin Medical University, Harbin 150086, China

${ }^{5}$ Training Center for Students Innovation and Entrepreneurship Education, Harbin Medical University, Harbin 150086, China

(c) The Author(s). 2021 Open Access This article is licensed under a Creative Commons Attribution 4.0 International License, which permits use, sharing, adaptation, distribution and reproduction in any medium or format, as long as you give appropriate credit to the original author(s) and the source, provide a link to the Creative Commons licence, and indicate if changes were made. The images or other third party material in this article are included in the article's Creative Commons licence, unless indicated otherwise in a credit line to the material. If material is not included in the article's Creative Commons licence and your intended use is not permitted by statutory regulation or exceeds the permitted use, you will need to obtain permission directly from the copyright holder. To view a copy of this licence, visit http://creativecommons.org/licenses/by/4.0/ The Creative Commons Public Domain Dedication waiver (http://creativecommons.org/publicdomain/zero/1.0/) applies to the data made available in this article, unless otherwise stated in a credit line to the data. 


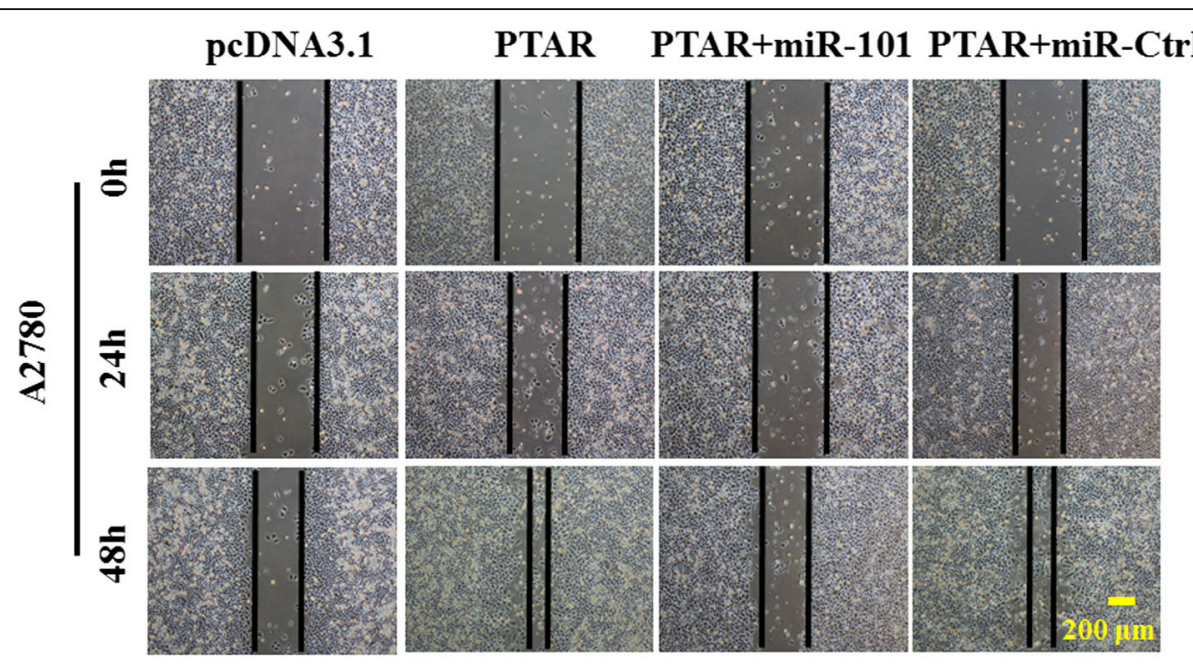

Fig. 3B

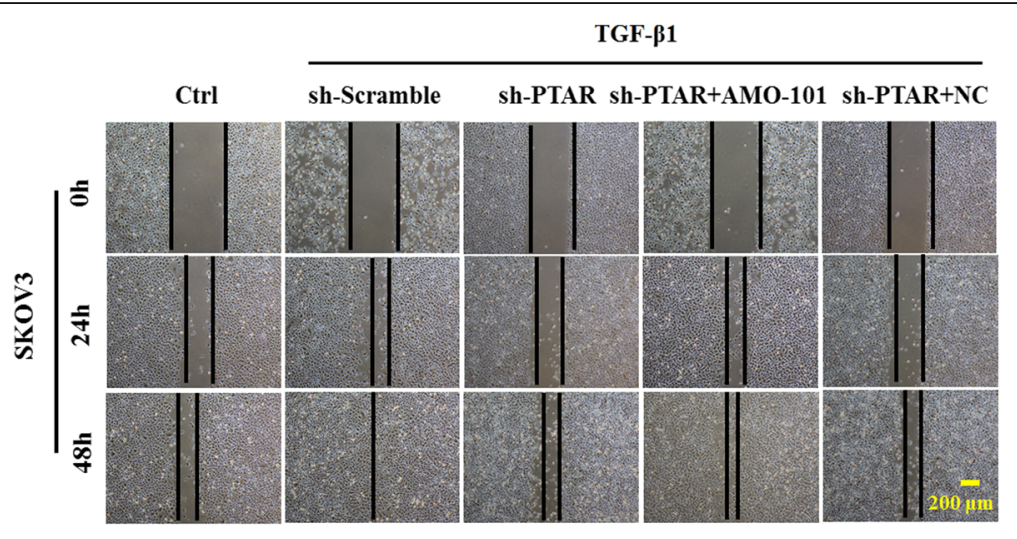

Fig. 4A 

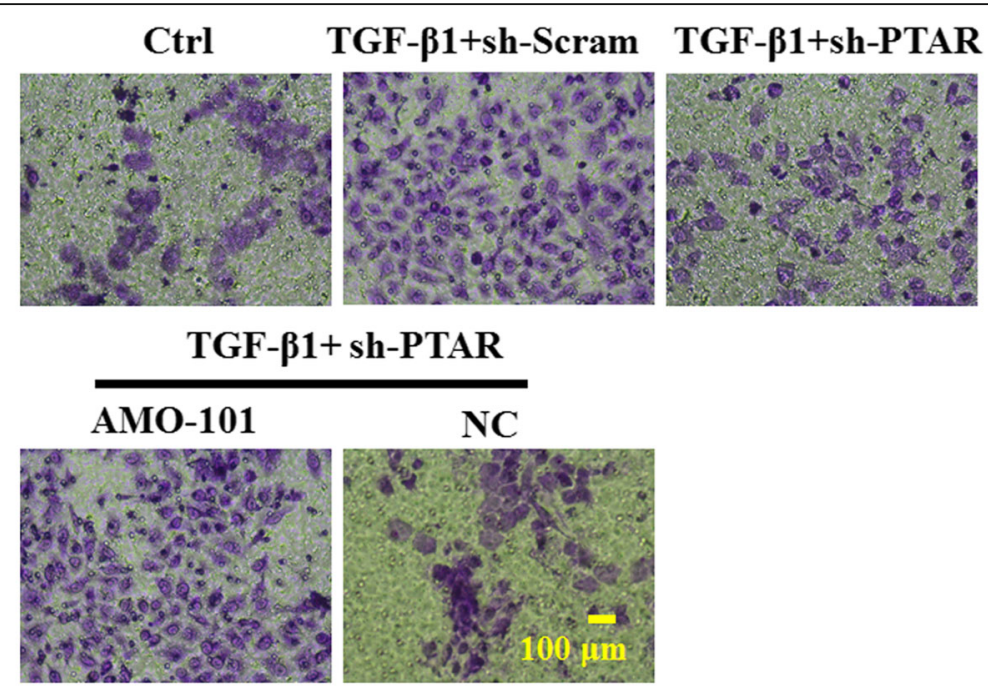

Fig. 4D

Ctrl

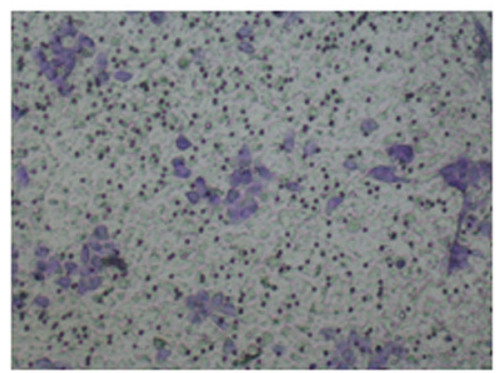

TGF- $\beta 1+$ miR-101 TGF- $\beta 1+m i R-C t r l$
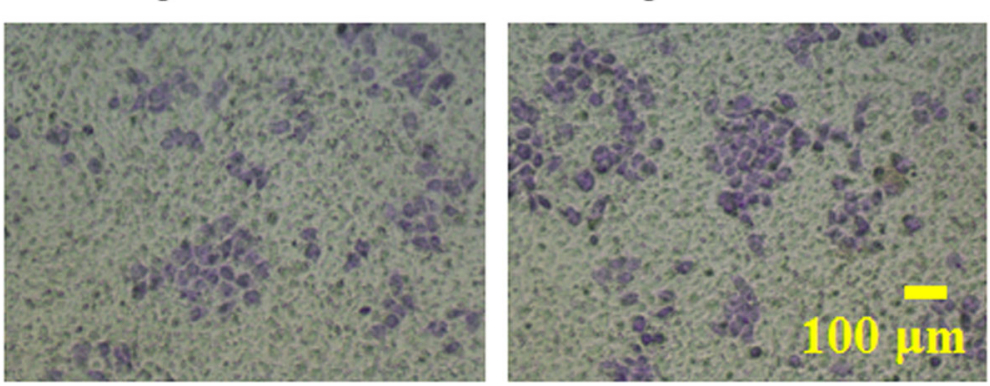

Fig. 7D

\section{TGF- $\beta 1$}

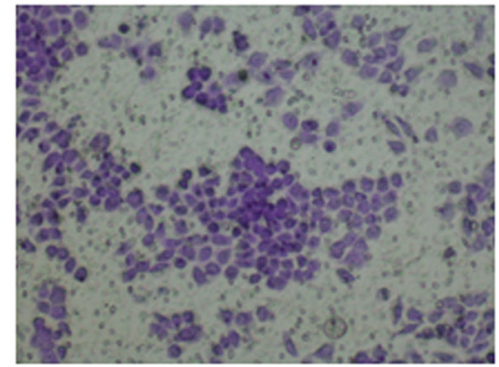

